\title{
Effect of Fly Ash on Leaching Characteristics of Cement-Stabilized Macadam Base
}

\author{
Dian Lun ${ }^{1}$, Taiping Yuan ${ }^{2}$, Xiaolong Yang ${ }^{1, * \mathbb{C}}$, Hongliu Rong ${ }^{1}$, Junjie Shi ${ }^{1}$ and Minqiang Pan ${ }^{1}$ \\ 1 College of Civil Engineering and Architecture, Guangxi University, Nanning 530004, China; \\ lundian2020@126.com (D.L.); ronghongliu@126.com (H.R.); shijunjie2021@126.com (J.S.); \\ minqiang73@163.com (M.P.) \\ 2 Energy Development Research Institute Co., Ltd., China Southern Power Grid, Guangzhou 510530, China; \\ yuantp@csg.cn \\ * Correspondence: xiaolongyang@gxu.edu.cn
}

Citation: Lun, D.; Yuan, T.; Yang, X.; Rong, H.; Shi, J.; Pan, M. Effect of Fly Ash on Leaching Characteristics of Cement-Stabilized Macadam Base. Materials 2021, 14, 5935. https:// doi.org/10.3390/ma14205935

Academic Editor: Luigi Coppola

Received: 7 September 2021

Accepted: 4 October 2021

Published: 9 October 2021

Publisher's Note: MDPI stays neutral with regard to jurisdictional claims in published maps and institutional affiliations.

Copyright: (c) 2021 by the authors. Licensee MDPI, Basel, Switzerland. This article is an open access article distributed under the terms and conditions of the Creative Commons Attribution (CC BY) license (https:// creativecommons.org/licenses/by/ $4.0 /)$.

\begin{abstract}
To study the leaching characteristics of a cement-stabilized macadam base with fly ash, a calcium leaching test, using varying cement and fly ash dosages in an ammonium chloride solution, was designed to obtain the rate of calcium ion leaching, porosity, and permeability coefficient of cement-stabilized macadam with leaching time. The results showed that the number of leached calcium ions increased with the cement dosage in the leaching of cement-stabilized macadam. With an increase in the cement dosage, the leaching rate of calcium ions decreased, and the leaching process of the material was delayed. The incorporation of fly ash could effectively slow down the degree of calcium ion leaching. The permeability coefficient increased gradually with the extension of leaching time, and the increase in fly ash content had a more significant effect on the improvement of the permeability coefficient than the increase in cement dosage did.
\end{abstract}

Keywords: cement-stabilized macadam base; leaching; fly ash; cement dosage

\section{Introduction}

Cement-stabilized macadam base, exhibiting good stability, strength, and low cost, has been widely used in China's highway construction. Cracks will inevitably occur in the pavement base, and pavement seepage and groundwater can enter the pavement base owing to its construction. However, the drainage performance of the pavement base is poor. Some of the water is retained between the surface and base, causing scouring damage to the pavement base, which is under a frequent load. Some of this seepage enters the pores in the base material, extracting calcium ions, resulting in road surface mud and potentially severe damage. Water damage is the main form of damage to cement-stabilized macadam bases. Existing research has focused mainly on scouring damage, and there is a lack of research on leaching loss.

Currently, some scholars at home and abroad have studied leaching problems. For example, Guo found that the axial compressive strength, splitting tensile strength, and quality of concrete gradually decreased with age owing to erosion. Guo also found that the degradation of the splitting tensile strength was more evident than that of the axial compressive strength [1]. Zhou et al. found that the elastic modulus, compressive strength, and splitting tensile strength of concrete decreased with increased leaching time [2]. Kong et al. found that leakage dissolution leads to a decrease in the mechanical properties of concrete and a significant decrease in the splitting tensile strength [3]. In a soft water dissolution environment, Guo found that the $\mathrm{Ca}^{2+}$ in the cement paste continued to leach, and the limit value of the cumulative leaching ratio of $\mathrm{Ca}(\mathrm{OH})_{2}$ in the sample was approximately $30-40 \%$ of the total. The number of years taken for the compressive strength of the cement slurry sample to decrease significantly was closely related to the water-binder ratio [4]. Deng et al. studied the law of calcium ion leaching in different cycles by measuring the calcium ion 
content in a corrosive solution [5-7]. Faucon found that a significant amount of calcium and a small amount of silicon were leached in the surface leaching area, and that the leaching of cement-based materials is an inherent problem. The local chemical equilibrium controls the leaching process of concrete in soft water, and the calcium leaching process is controlled by the diffusion of calcium ions $[8,9]$. Haga conducted an experimental study on the leaching of cement stone with varying water-cement ratios. The results showed that the porosity increased continuously with the leaching of calcium ions, and that the increase in porosity accelerated the diffusion and leaching of calcium ions [10]. Tognazzi established an empirical relationship between the effective diffusion coefficient of calcium ions and porosity [11]. Bilal's study showed that the morphological changes caused by calcium leaching indicated that the solid volume fraction in the cement matrix decreased, thereby increasing the porosity, and ultimately, reducing the strength and durability of permeable concrete [12]. Song et al. studied the leaching behavior of calcium in one dimension (the other four surfaces of the test sample were sealed, and the leaching rates of calcium ions from the upper surface to the lower surface of the test sample were analyzed) in a cement slurry by immersing the samples in an $\mathrm{NH}_{4} \mathrm{Cl}$ solution. They found that the electrical resistance in the leaching zone increased, which can be used as a measure to characterize the degree of leaching [13]. Amenta et al. accelerated the leaching at a voltage of $30 \mathrm{~V}$. Their SEM results confirmed the migration of $\mathrm{Ca}^{2+}$ and the self-repair mechanism of newly formed calcite precipitated in the microstructure of cement-based materials [14]. Long et al. studied the leaching resistance of graphene oxide using the deionized water leaching method, and considered that the oxygen-containing functional groups of graphene oxide could capture $\mathrm{Ca}^{2+}$ and reduce the leaching of calcium [15].

According to research and surveys, approximately 1.3 billion tons of fly ash waste is produced globally every year; however, its recycling rate is low, and approximately $47 \%$ of the fly ash waste goes to landfills. The existence of several fly ash landfills will negatively affect the ecological environment and human health [16]. Fly ash is a pozzolanic active material. Its main chemical components are $\mathrm{SiO}_{2}$ and $\mathrm{Al}_{2} \mathrm{O}_{3}$, and its mineral is mainly an aluminum-silicon vitrified structure. The application of fly ash in cement-based materials can improve the strength and durability of these materials, and may mitigate the harm caused by fly ash to the environment. The primary mechanism of action of fly ash in cement-based materials is based on its physical activity: particle, micro-aggregate, and compactness effect [17]. Ferdous et al. found that adding fillers, such as fly ash, to the resin improves the heat resistance and durability of the epoxy matrix [18]. Yu et al. mixed epoxy resin with a flame-retardant filler, fly ash, and other functional fillers to improve the durability [19]. Fang studied the pore structure and leaching resistance of RCC (roller-compacted concrete) with low cement and high fly ash content [20]. Roziere's research showed that the addition of fly ash reduced the calcium hydroxide content in the concrete and decreased the soluble calcium hydroxide content in the material, thereby decreasing the degree of leaching damage [21]. Roziere's research also showed that fly ash alone can slow down the calcium leaching process of cement paste and improve its corrosion resistance in deionized water [22]. Through microscopic analysis, Sun found that, when the fly ash content was not more than $50 \%$, the calcium silicate hydrate (CSH) content increased continuously, and the number of nondetrimental pores increased significantly [6]. In Sun's investigation, it was found that the addition of fly ash could reduce the porosity. However, Fang's test results showed that, although the addition of fly ash reduces the calcium hydroxide $(\mathrm{CH})$ content and the number of calcium ions leached out, it increases the porosity of the sample, and accelerates the calcium leaching process of the material [23].

Existing research on the leaching and scouring of cement-stabilized macadam base has mainly focused on the thermodynamics of dissolution and precipitation reactions of the calcium hydroxide produced by the hydration of cement and the decomposition reaction kinetics of calcium silicate hydrate. Other aspects include the migration mechanism of corrosion reaction products in concrete, micro-characterization of pore structure, and porosity changes caused by corrosion. However, it is challenging to achieve dissolution equilibrium 
under the action of ambient water, and the change in the base material properties caused by dissolution has not been studied thoroughly. Moreover, there are few studies on the influence of fly ash on the dissolution properties of cement-stabilized macadam materials.

During the leaching process of cement-based materials, the solution in the pores continuously diffuses out to dissolve the calcium hydroxide, resulting in a decrease in the $\mathrm{pH}$ of the pore solution. Concurrently, the dissolution of solid-phase-bound calcium also produces more pores in the cement-based materials and increases the connectivity of the interior pores. Therefore, in the research on calcium leaching of cement-based materials, the quantity of leached calcium ions and the change in porosity are commonly used to characterize the calcium leaching process [3,5-11].

Therefore, to study the leaching characteristics of cement-stabilized macadam with fly ash, an accelerated leaching test of cement and fly ash with varying additions of ammonium chloride solution was designed. The variations in calcium ion leaching, porosity, and permeability of cement-stabilized macadam were obtained through tests, and the results were analyzed accordingly.

\section{Materials and Methods}

\subsection{Materials}

\subsubsection{Cement}

In this study, $\mathrm{P} \times \mathrm{O} 42.5$ Portland cement was used. According to the Methods for Chemical Analysis of Cement (GB/T 176-2017), the chemical composition is shown in Table 1, and the mineral compositions are shown in Table 2.

Table 1. Chemical composition of cement.

\begin{tabular}{ccccccc}
\hline Chemical Compositions & $\mathrm{SiO}_{2}$ & $\mathrm{Al}_{2} \mathrm{O}_{3}$ & $\mathrm{Fe}_{2} \mathrm{O}_{3}$ & $\mathrm{CaO}$ & $\mathbf{M g O}$ & $\mathrm{SO}_{3}$ \\
\hline Content $(\%)$ & 20.10 & 4.63 & 3.46 & 63.62 & 1.18 & 2.01 \\
\hline
\end{tabular}

Table 2. Mineral composition of cement.

\begin{tabular}{|c|c|c|c|c|c|}
\hline $\begin{array}{c}\text { Mineral } \\
\text { Compositions }\end{array}$ & $\mathrm{C}_{3} \mathrm{~S}$ & $\mathrm{C}_{2} \mathrm{~S}$ & $\mathrm{C}_{3} \mathrm{~A}$ & $\mathrm{C}_{4} \mathrm{AF}$ & $\mathrm{C} \bar{S} \mathrm{H}_{2}$ \\
\hline Content (\%) & 64.39 & 9.08 & 6.42 & 10.53 & 4.32 \\
\hline
\end{tabular}

\subsubsection{Fly Ash}

Grade I low-calcium fly ash was used, and its chemical composition is listed in Table 3.

Table 3. Chemical composition of fly ash.

\begin{tabular}{ccccccc}
\hline Components & $\mathrm{SiO}_{\mathbf{2}}$ & $\mathbf{C a O}$ & $\mathbf{A l}_{2} \mathbf{O}_{3}$ & $\mathbf{F e}_{\mathbf{2}} \mathbf{O}_{3}$ & $\mathbf{M g O}$ & Others \\
\hline Content $(\%)$ & 53.36 & 2.27 & 29.09 & 3.87 & 0.81 & 10.6 \\
\hline
\end{tabular}

\subsubsection{Aggregate}

The aggregates used herein were gravel and river sand. The fraction with a particle size greater than $4.75 \mathrm{~mm}$ was used as the coarse aggregate. The fine aggregate was river sand. The crushing value of the gravel material was $20.6 \%$, and the water content of the aggregate was $0.3 \%$. The apparent density of the fine aggregate was $2.58 \mathrm{~g} / \mathrm{cm}^{3}$. After examination, each index of the aggregate met the requirements of the specifications.

\subsubsection{Water for Test}

The cement-stabilized macadam was prepared with potable water. Moreover, $6 \mathrm{~mol} / \mathrm{L}$ of ammonium chloride solution and EDTA (Ethylene Diamine Tetraacetic Acid) standard solution were prepared with deionized water ( $\mathrm{pH} 7.0)$. 


\subsubsection{Ammonium Chloride}

Ammonium chloride solution tests were prepared using ammonium chloride powder. The ammonium chloride content was not less than $99.5 \%$, and the relative molecular mass was 53.49. The solubility of the ammonium chloride in water at room temperature is approximately $37.2 \mathrm{~g} / 100 \mathrm{~mL}$.

\subsubsection{EDTA Standard Titration Solution}

According to the Test Methods of Materials Stabilized with Inorganic Binders for Highway Engineering (JTG E51-2009), analytical-reagent-grade disodium EDTA was used to produce the standard titration solutions of EDTA at 10 and $100 \mathrm{mmol} / \mathrm{L}$. In addition, 1:1 diluted hydrochloric acid and 20\% sodium hydroxide solution, CMP indicator, E44 epoxy resin were used.

\subsection{Mixture Design}

\subsubsection{Gradation Design}

The results of the grain-gradation calculations at differing remaining voids are shown in Table 4.

Table 4. Particle size distribution design with differing residual voids.

\begin{tabular}{cccccc}
\hline \multirow{2}{*}{ Sieve Size (m) } & \multicolumn{5}{c}{ Percentage of Pass at Different Residual Voids (\%) } \\
\cline { 2 - 6 } & $\mathbf{3 \%}$ & $\mathbf{4 \%}$ & $\mathbf{5 \%}$ & $\mathbf{6 \%}$ & $\mathbf{7 \%}$ \\
\hline 31.5 & 100 & 100 & 100 & 100 & 100 \\
19.0 & 67 & 70 & 72 & 73 & 74 \\
9.5 & 46 & 49 & 51 & 54 & 55 \\
4.75 & 31 & 34 & 37 & 39 & 41 \\
2.36 & 21 & 24 & 26 & 29 & 31 \\
1.18 & 14 & 17 & 19 & 21 & 23 \\
0.6 & 10 & 12 & 14 & 15 & 17 \\
0.3 & 7 & 8 & 10 & 11 & 13 \\
0.15 & 4 & 6 & 7 & 8 & 9 \\
0.075 & 3 & 4 & 5 & 6 & 7 \\
$n$ & 5.420 & 5.595 & 5.735 & 5.853 & 5.954 \\
\hline
\end{tabular}

The cement/fly ash ratios mixed into the macadam were 1:0.1, 1:0.2, and 1:0.3, which were compared with samples without fly ash.

\subsubsection{Optimal Water Content and Maximum Dry Density}

The water content-dry density curve of the mixture was drawn from the results obtained using the heavy compaction method, according to the Test Methods of Materials Stabilized with Inorganic Binders for Highway Engineering (JTG E51-2009). This allowed the optimum water content and maximum dry density of the sample to be determined. Samples with five different water contents were prepared for each fly ash level. The test results are presented in Table 5.

\subsubsection{Preparation and Maintenance of Samples}

All test pieces were shaped using static pressure. After demolding, the samples were sealed in plastic bags and held for 90 days in standard maintenance rooms at a temperature of $20 \pm 2{ }^{\circ} \mathrm{C}$ and a relative humidity of more than $95 \%$. According to the results in Table 5 , three parallel specimens were made for each variable. The samples obtained after this process were sealed with epoxy resin to ensure that they were only leached in the axial direction. Each sample was cut into two halves, half of which was taken to be the test block. As shown in Figure 1, these are the specimens prepared in the experiment. 
Table 5. Compaction test results of cement-stabilized macadam.

\begin{tabular}{ccccc}
\hline NO. & Cement Dosage & Cement: Fly Ash & $\begin{array}{c}\text { Optimum } \\
\text { Water Content }\end{array}$ & $\begin{array}{c}\text { Maximum } \\
\text { Dry Density }\end{array}$ \\
\hline C3FA0 & & $1: 0$ & 4.11 & 2.213 \\
C3FA1 & $3 \%$ & $1: 0.1$ & 4.12 & 2.224 \\
C3FA2 & & $1: 0.2$ & 4.22 & 2.233 \\
C3FA3 & $1: 0.3$ & 4.30 & 2.247 \\
\hline C4FA0 & & $1: 0$ & 4.41 & 2.251 \\
C4FA1 & $4 \%$ & $1: 0.1$ & 4.52 & 2.273 \\
C4FA2 & & $1: 0.2$ & 4.65 & 2.284 \\
C4FA3 & & $1: 0.3$ & 4.73 & 2.295 \\
\hline C5FA0 & & $1: 0$ & 4.60 & 2.290 \\
C5FA1 & $5 \%$ & $1: 0.1$ & 4.65 & 2.331 \\
CFA2 & $1: 0.2$ & 4.76 & 2.353 \\
C5FA3 & & $1: 0.3$ & 4.82 & 2.390 \\
\hline C6FA0 & & $1: 0$ & 4.93 & 2.362 \\
C6FA1 & \multirow{2}{*}{$\%$} & $1: 0.1$ & 5.02 & 2.401 \\
C6FA2 & & $1: 0.2$ & 5.13 & 2.436 \\
C6FA3 & & $1: 0.3$ & 5.46 & 2.473 \\
\hline C7FA0 & & $1: 0$ & 5.24 & 2.440 \\
C7FA1 & \multirow{2}{*}{$\%$} & $1: 0.1$ & 5.31 & 2.443 \\
C7FA2 & & $1: 0.2$ & 5.44 & 2.448 \\
C7FA3 & & $1: 0.3$ & 5.72 & 2.451 \\
\hline
\end{tabular}
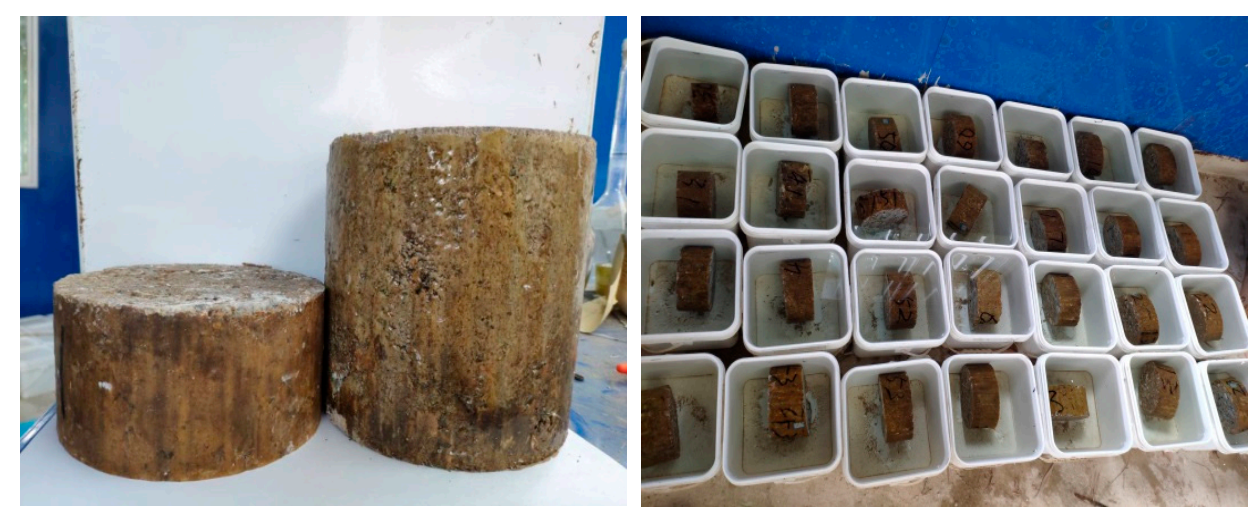

Figure 1. Cement-stabilized macadam samples.

\subsection{Experimental Methods}

\subsubsection{Accelerated Leaching of Ammonium Chloride}

Gérard performed an accelerated concrete leaching test with a $6 \mathrm{~mol} / \mathrm{L} \mathrm{NH}_{4} \mathrm{NO}_{3}$ solution, proposed a 1D simulation model of calcium leaching of concrete, and verified the model's reliability [24]. Subsequently, many scholars globally have used this method to study the mechanism of calcium leaching $[2,5,10,25-27]$. Research shows that little difference exists between accelerated leaching with ammonium chloride solution and that under a natural environment [10]. Therefore, a $6 \mathrm{~mol} / \mathrm{L}$ ammonium chloride solution was used to accelerate the leaching test.

The ammonium chloride-accelerated leaching method was used to simulate the leaching process. First, a $6 \mathrm{~mol} / \mathrm{L}$ ammonium chloride solution was prepared. The sample was then placed in the ammonium chloride solution for dissolution corrosion; it was ensured that the upper and lower surfaces were in complete contact with the solution. Finally, the container was sealed during leaching. During the leaching process, the calcium ion concentration in the corrosion solution was measured every two days. The porosity and 
permeability coefficient of the sample were measured at intervals of four and eight days. The total test period was 28 days.

\subsubsection{Calcium Ion Concentration Determination}

After the corrosion solution was thoroughly mixed, $5 \mathrm{~mL}$ of solution was taken and diluted $\mathrm{X}$ times with deionized water. Next, $50 \mathrm{~mL}$ of aliquot was added to an Erlenmeyer flask. Then, three drops of dilute hydrochloric acid (1:1) were added. The solution was then boiled to discharge the carbon dioxide. Then, $5 \mathrm{~mL}$ of $20 \%$ sodium hydroxide solution and $80 \mathrm{mg}$ of the calcein indicator were added to the flask and titrated against the EDTA solution. The solution was titrated with the configured EDTA solution. The initial volume, $V_{1}$, was recorded. The titration endpoint is represented by a change from yellow/green to orange/red, as shown in Figure 2. The final volume, $V_{2}$, was recorded. The calcium ion concentration was calculated as follows:

$$
C=\frac{\left(V_{2}-V_{1}\right) \times M \times X}{V_{W}}
$$

where $V_{1}, V_{2}$ are the volumes of the EDTA solution before and after the test $(\mathrm{mL})$, respectively; $M$ is the EDTA concentration $(\mathrm{mmol} / \mathrm{L}) ; X$ is the dilution factor of the solution to be tested; $V_{W}$ is the test solution volume $(\mathrm{mL})$.

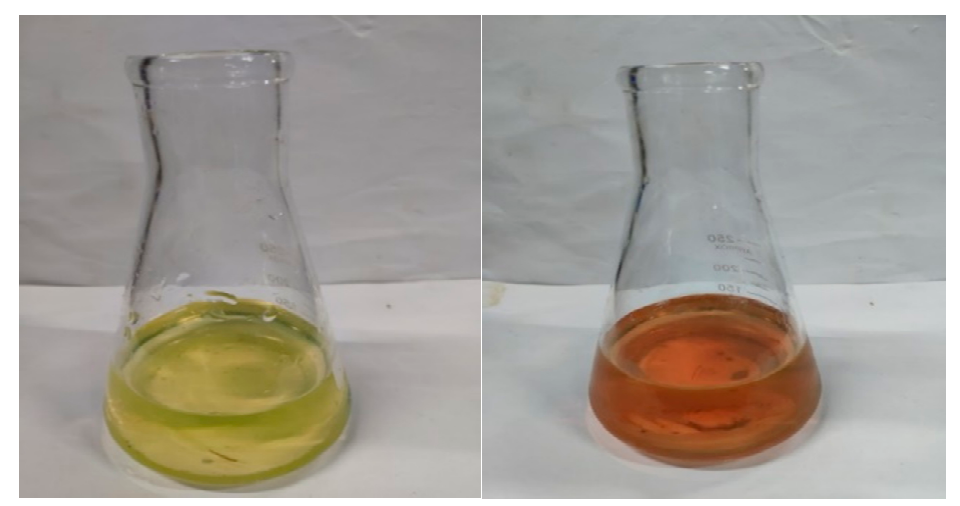

(a)

(b)

Figure 2. Color change of solution before and after titration: (a) color before titration; (b) color after titration.

\subsubsection{Porosity Test}

According to the ASTM C1202, we experimented with the saturated water-dry weighing method. First, the leached sample was removed from the solution. Next, the excess water on the surface was wiped off with a towel and weighed. Then, the sample was completely immersed in water and weighed using a hanging scale. Subsequently, the sample was placed in an oven at $60^{\circ} \mathrm{C}$ and dried to a constant weight, which was recorded. Finally, the porosity of the sample was calculated as:

$$
\varphi=\frac{m_{s}-m_{d}}{m_{s}-m_{x}} \times 100 \%
$$

where $m_{s}$ is the saturated mass of the sample $(\mathrm{g}) ; m_{x}$ is the mass of the sample immersed in water $(\mathrm{g}) ; m_{d}$ is the mass of the sample after drying $(\mathrm{g})$.

\subsubsection{Water Permeability}

Using the methods for inorganic binders as stabilizing materials in highway engineering (JTG E51-2009), the diameter of the base of the seepage meter was set to $100 \mathrm{~mm}$, and the permeability coefficient of the sample was measured by changing the head. First, the sample was padded to ensure that the seepage was unhindered. Then, the bottom of 
the instrument was placed on top of the test sample, and the contact area between the instrument and sample was sealed to prevent water seepage from affecting the test results. Next, the instrument was filled with water to a suitable depth, and the lower switch was opened quickly. When the water level dropped to $V_{1}=100 \mathrm{~mL}$, the recording time started. As the descent process was slow, only a 3 min seepage volume was used to calculate the permeability coefficient. The volume $V_{2}$ in the seepage pipe was recorded at this time. Finally, the permeability coefficient was calculated as

$$
C_{W}=\frac{V_{2}-V_{1}}{t}
$$

where $V_{1}, V_{2}$ are the volumes of water in the container before and after the test $(\mathrm{mL})$, respectively; $t$ is the time taken for testing ( $\mathrm{min}$ ).

If the sample was not corroded, $\mathrm{Ca}(\mathrm{OH})_{2}$ in the test piece turned magenta when exposed to phenolphthalein. If the test piece was leached, the calcium ions in the sample would leach out, and the sample would not change color when exposed to phenolphthalein. Using this distinction, the degree of corrosion of the sample was estimated.Figure 3 shows that, over time, the color development of phenolphthalein gradually decreased. That is, the degree of leaching of the sample decreased, and the calcium ions were almost completely leached.

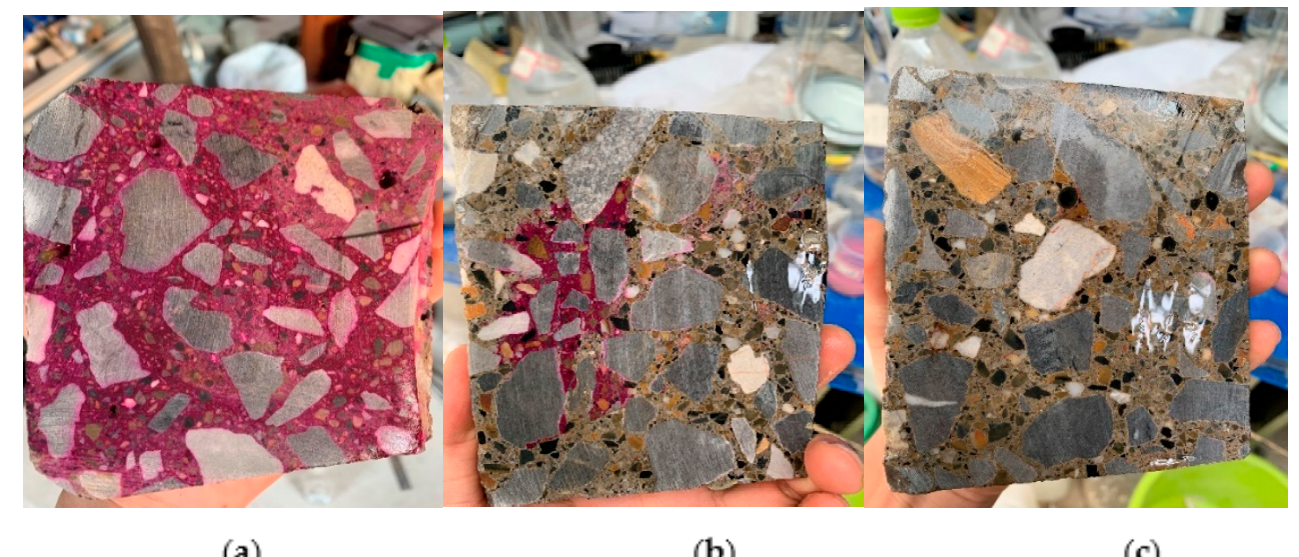

(a)

(b)

(c)

Figure 3. Phenolphthalein indicator shows changes in solution: (a) $0 \mathrm{~h}$; (b) $1 \mathrm{~h}$; (c) $2 \mathrm{~h}$.

\section{Results and Discussion}

\subsection{Leaching Amount of Calcium Ion}

\subsubsection{Effect of Cement Dosage on Calcium Ion Concentration}

Figure $4 \mathrm{a}-\mathrm{d}$ show the calcium ion concentration change in the ammonium chloride corrosion solution over time with different cement dosages and fly ash contents. When the amount of fly ash was fixed, the calcium ion concentration increased with the cement dosage. This was because the pore calcium ions in contact with the solution in the sample reacted with ammonium chloride, disrupting the dissolution balance of calcium ions in the pore. Consequently, the solid-phase calcium ions continuously dissolved into the pore solution. This resulted in a difference in the concentration of calcium ions in the pores of the solution. Thus, the calcium ions in the pores continued to disperse into the solution. Finally, the calcium ion concentration in the $\mathrm{NH}_{4} \mathrm{Cl}$ solution increased continuously. Increased cement dosage increased the contact area between the cement hydration products and corrosive fluid. Therefore, the probability of leaching of calcium ions by corrosion increased, which ultimately led to an increase in the content of calcium ions in the corrosion solution. 


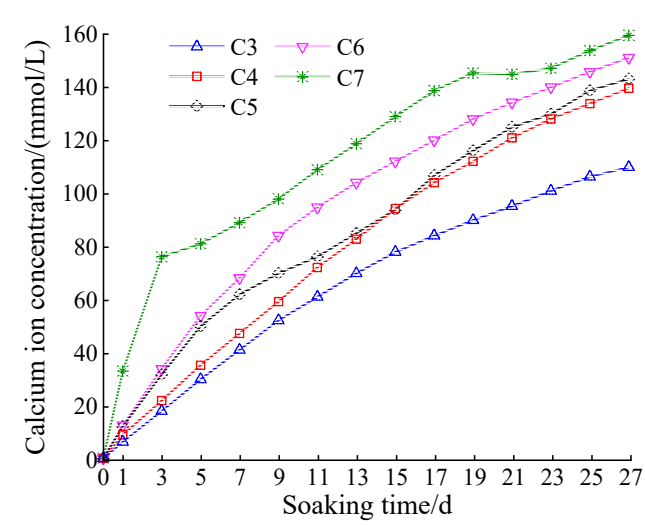

(a)

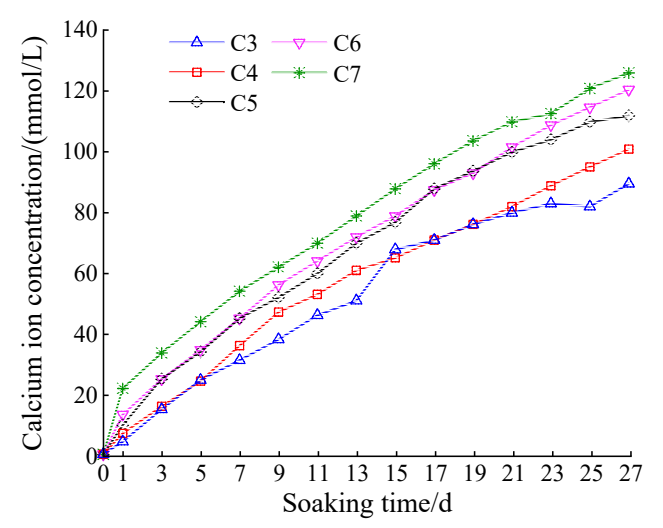

(c)

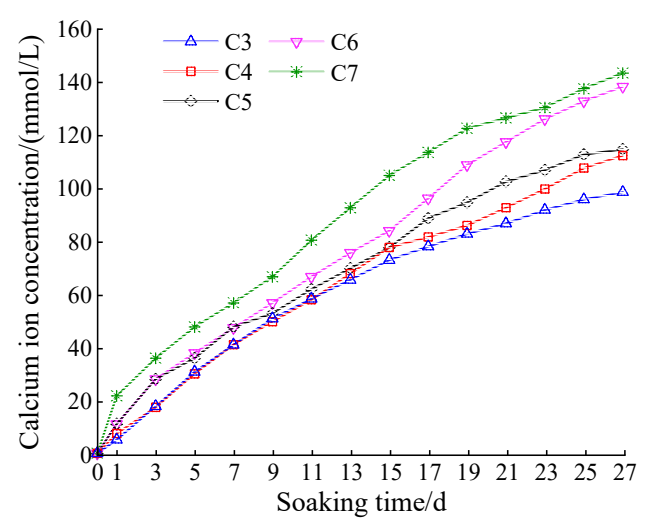

(b)

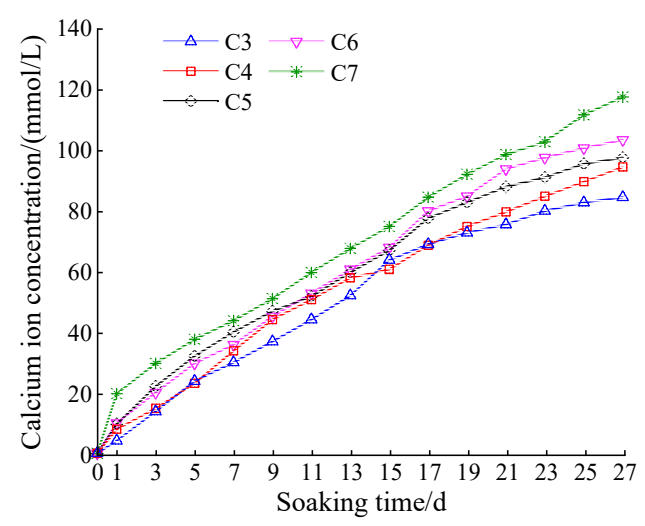

(d)

Figure 4. Calcium ion concentration curve at different cement dosages: (a) cement:fly ash = 1:0; (b) cement:fly ash =1:0.1; (c) cement:fly ash =1:0.2; (d) cement:fly ash =1:0.3.

Figure $4 a-d$ show that, when the cement dosage was $7 \%$ and no fly ash was added, the concentration of calcium ions leached out at the early stage of leaching was significantly greater than those at other cement dosages. However, with the increase in fly ash content, the gap between the two was significantly reduced. The former was because, when the cement dosage reached $7 \%$, some cement hydration products were not involved in the stability of the gravel, but remained on the outside of the sample. Consequently, a considerable amount of calcium hydroxide reacted with ammonium chloride at the early stage of leaching, and the concentration of calcium ions in the corrosive solution was higher than those in other cement dosages. The latter was because a considerable amount of calcium hydroxide was converted into hydrated calcium silicate by the addition of fly ash, and the dissolution rate of hydrated calcium silicate was reduced. Therefore, the quantity of calcium ions leached out was small in the early stage of leaching.

\subsubsection{Effect of Cement Dosage on the Calcium Ion Leaching Rate}

According to Figure $5 \mathrm{a}-\mathrm{d}$, when the amount of fly ash was constant, the leaching rate of calcium ions decreased gradually with the cement dosage. This was because an increase in the cement and fly ash dosage reduced the porosity of the sample. However, the leaching process of the material started from the outside and progressed inside. When the porosity decreases, it is more difficult for the corrosive solution to enter the pores of the material, and the calcium ion leaching rate (the ratio of leached calcium ions to the calcium content of $\mathrm{CH}$ and $\mathrm{CSH}$ in the specimen) decreases. 


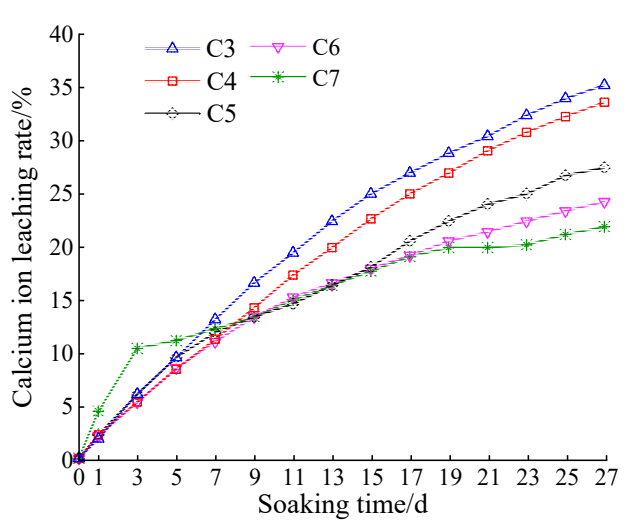

(a)

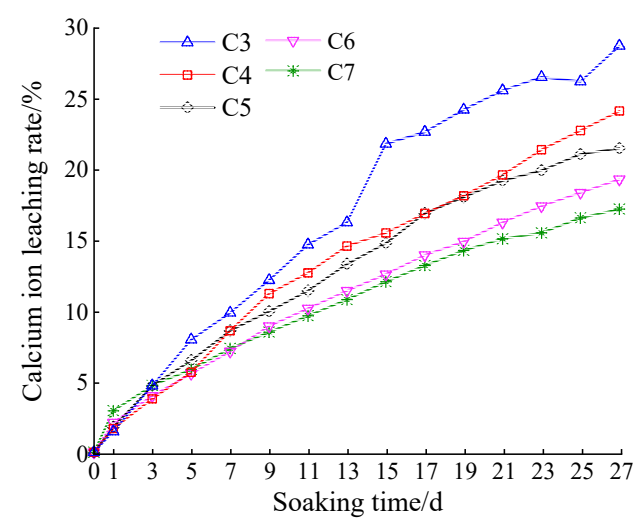

(c)

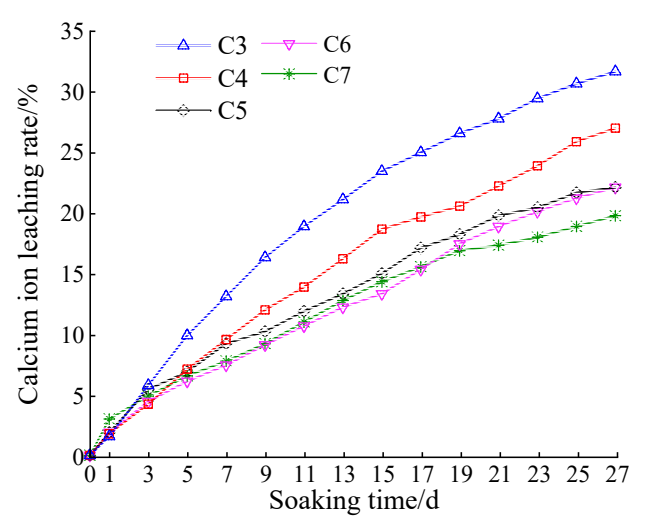

(b)

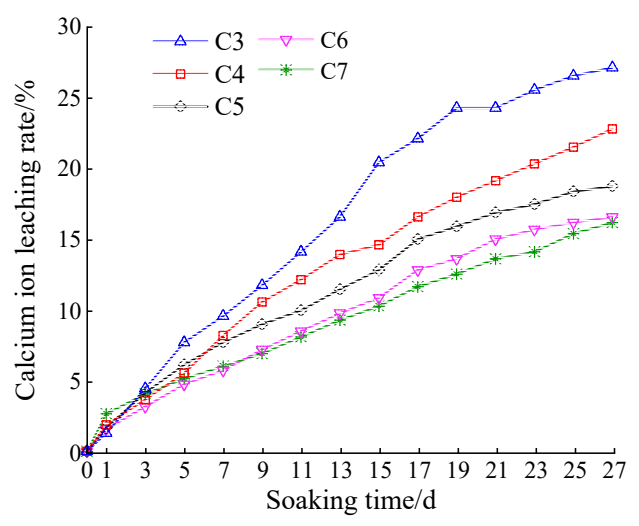

(d)

Figure 5. Variation curves of Ca ion dissolution rate at different cement dosages: (a) cement:fly ash $=1: 0$; (b) cement:fly ash =1:0.1; (c) cement:fly ash =1:0.2; (d) cement:fly ash =1:0.3.

Figure 5 a shows that, when fly ash was not added, the calcium ion leaching rates of the $3 \%$ and $4 \%$ cement samples were significantly higher than those of the other cement samples. Figure $5 b-d$ show that, when fly ash was added, the leaching rate of the calcium ions at a cement dosage of $4 \%$ was significantly improved. When the cement dosage was $3 \%$, the leaching rate of calcium ions decreased, although it was still higher than those at other cement dosages. When the cement dosage was $3 \%$, the leaching rate of the calcium ions decreased; however, it was still larger than those at other cement dosages. Therefore, the leaching damage caused by calcium ion leaching can be mitigated by increasing the cement dosage. When the base material is not mixed with fly ash, a $5 \%$ cement dosage should be considered as the lowest dosage. When the fly ash is mixed in the base material, a $4 \%$ cement dosage should be considered as the lowest dosage.

\subsubsection{Effect of Fly Ash Content on Calcium Ion Concentration}

According to the analysis of Figure 6a-e, when the cement dosage was fixed, the amount of calcium ion leaching decreased gradually with fly ash content. However, the quantity of calcium ions leached out under different cement dosages and fly ash contents was slightly different. When the cement dosage was 3\%, the addition of fly ash did not significantly reduce the leaching of calcium ions. When the cement dosage was more than $3 \%$, the slowing effect of the fly ash on calcium ion release increased with cement dosage. This is because, when the content of fly ash is relatively small, a significant amount of active silica in the fly ash reacts fully with the cement hydration products, which significantly reduces the content of calcium hydroxide in the samples and increases the content of hydrated calcium silicate $[28,29]$. In addition, during the leaching process, 
hydrated calcium silicate is more difficult to dissolve than calcium hydroxide, which results in a decrease in the amount and rate of calcium ion dissolution. Others believe that the leaching of calcium ions is also related to the calcium-silicon ratio in the mixture [30]. When the molar ratio of $\mathrm{CaO} / \mathrm{SiO}_{2}$ in the mixture was greater than $1, \mathrm{CaO}$ could easily be leached. When the molar ratio of $\mathrm{CaO} / \mathrm{SiO}_{2}$ was less than $1, \mathrm{SiO}_{2}$ leaching occurred more easily. When the molar ratio of $\mathrm{CaO} / \mathrm{SiO}_{2}$ in the mixture was close to 1 , the leaching of both was negligible. The addition of fly ash changed the ratio of $\mathrm{CaO} / \mathrm{SiO}_{2}$ to make it closer to 1 , thus reducing the leaching rate of the calcium ions.

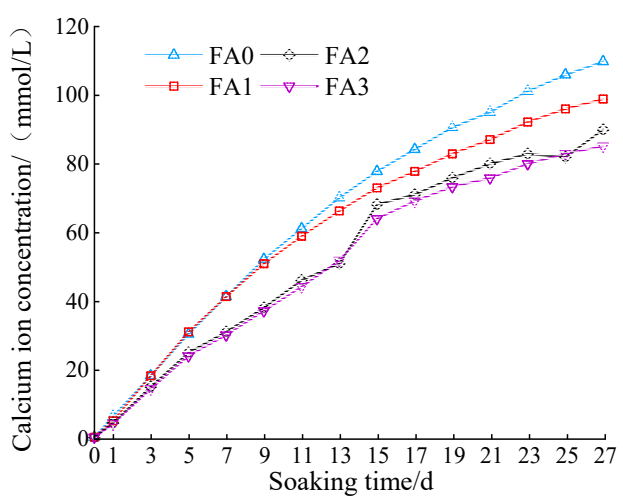

(a)

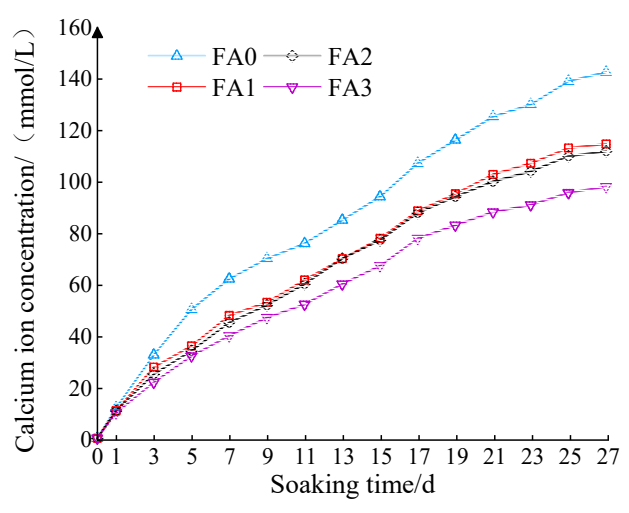

(c)

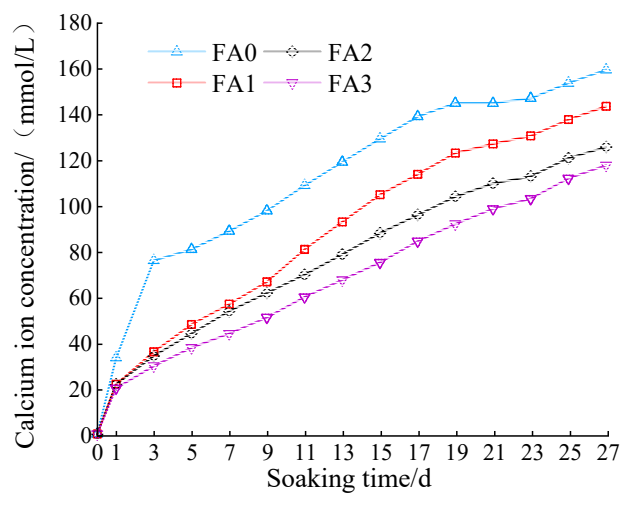

(e)

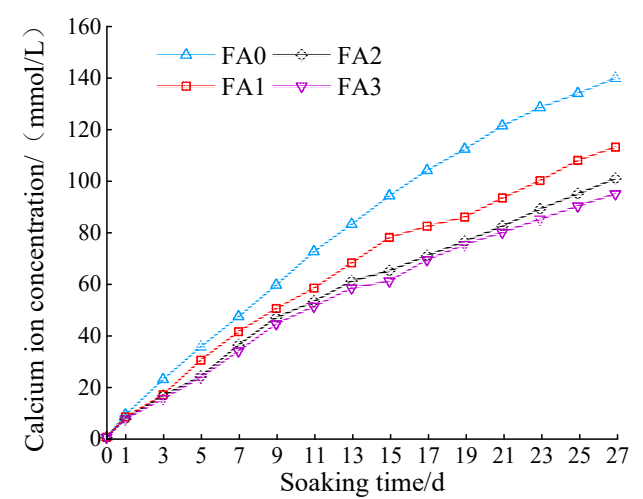

(b)

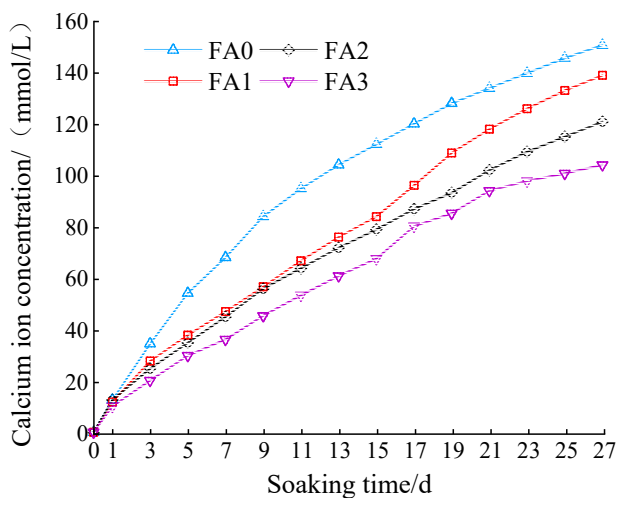

(d)

Figure 6. Variation curves of calcium ion concentration at different fly ash contents: (a) cement content: $3 \%$; (b) cement content: $4 \%$; (c) cement content: $5 \%$; (d) cement content: $6 \%$; (e) cement content: $7 \%$. 


\subsection{Porosity Variation}

\subsubsection{Effect of Cement Dosage on Porosity}

Figure 7a-d show that the porosity increased with the leaching time. When the fly ash content was constant, the porosity gradually decreased with the cement dosage.

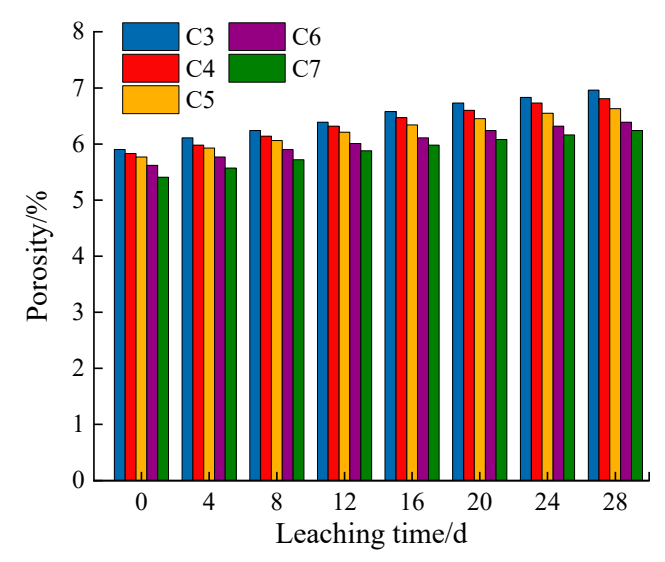

(a)

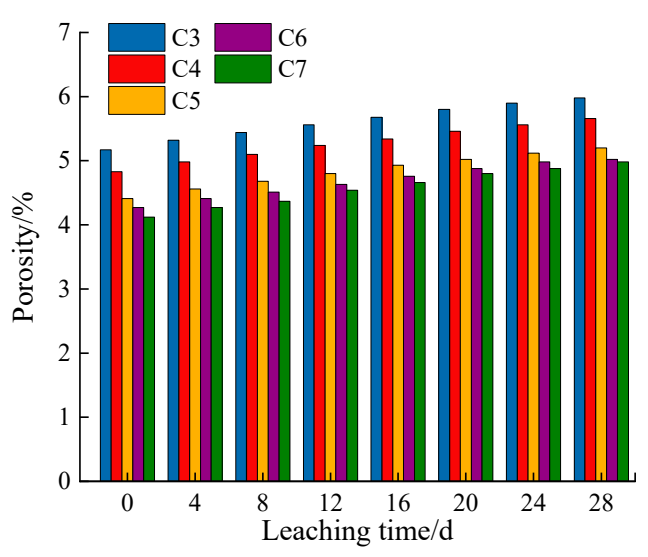

(c)

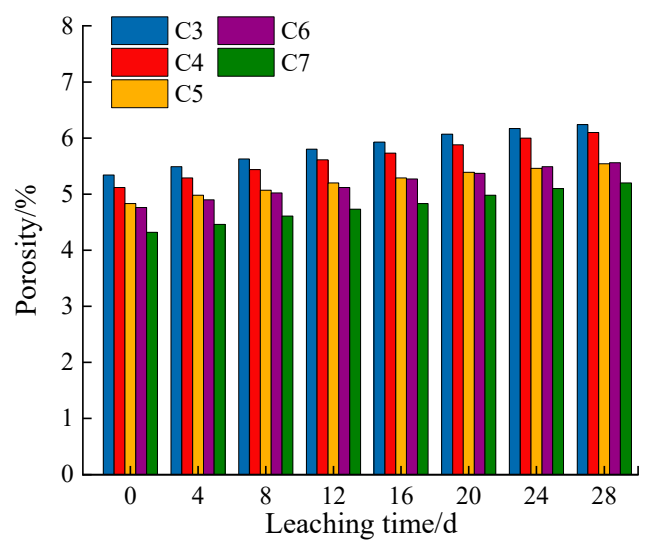

(b)

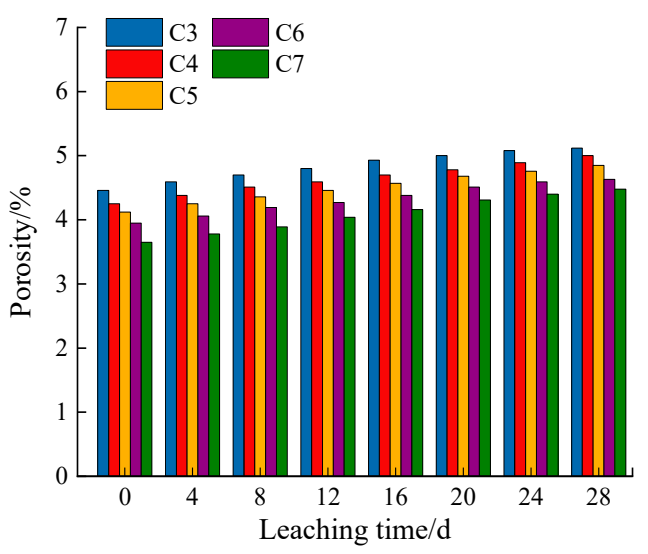

(d)

Figure 7. Porosity changes of samples with different cement dosages: (a) cement:fly ash $=1: 0$; (b) cement:fly ash $=1: 0.1 ;(\mathbf{c})$ cement:fly ash $=1: 0.2 ;(\mathbf{d})$ cement:fly ash $=1: 0.3$.

This was because the cement hydration products covered the crushed stones and filled the remaining pores in the process of sample formation. When the cement dosage increased, more hydration products filled the remaining pores, decreasing the remaining porosity. In addition, an increase in the cement dosage will inevitably lead to an increase in the hydration products. More active silica in the fly ash reacts with calcium hydroxide to form calcium silicate hydrate $[28,29]$. Calcium hydroxide mainly generates the pores. Hydrated calcium silicate mainly produces gel pores, which leads to a decrease in the number of pores and an increase in the number of gel pores [28,29]. However, because the number of pores is higher than that of the gel pores, the porosity of the entire sample decreases.

As shown in Figure 8, the content of fine crushed stones in the corrosive liquid bucket changed. During the test, it was found that the fine crushed stones falling off because of the loss of surface cement cementation in the corrosive solution gradually increased with time. The falling off of fine crushed stones caused the internal hydration products to contact the corrosive solution and aggravate the degree of leaching. 

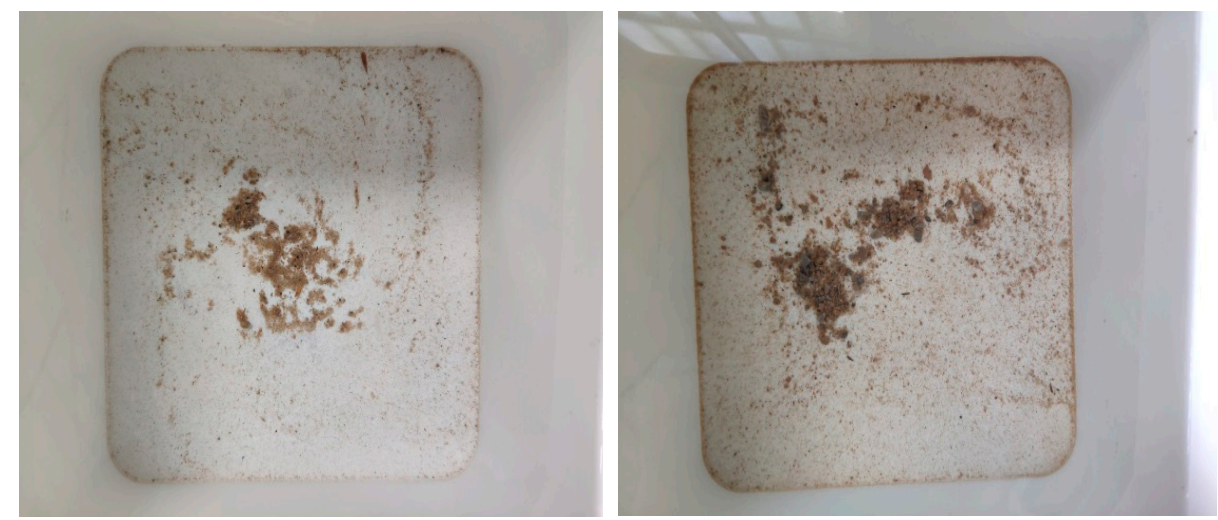

Figure 8. Change in fine gravel content in the corrosive liquid drum.

\subsubsection{Influence of Fly Ash Content on the Porosity}

According to the analysis of Figure 9a-e, when the cement dosage was constant, the porosity decreased with the fly ash dosage. This is because, in the cement fly ash-stabilized macadam system, the fly ash mainly exhibits a pozzolanic and micro-aggregate effect [16]. The pozzolanic effect occurs in the early stage of the strength formation of cement-stabilized macadam. The rapid hydration of cement provides early strength and produces a significant amount of calcium hydroxide. The fly ash, containing active silica, can react with calcium hydroxide to produce hydrated calcium silicate with smaller pores, which reduces the overall porosity of the sample [29,31-33]. The micro-aggregate effect occurs when the fly ash is added to the cement-stabilized macadam material. The aggregate without the fly ash is not compact. The spherical particles of the fly ash can fill the micropores formed by the sand, and the aggregate compactness is significantly improved [31-33]. The cement hydration products are filled and dispersed between the fly ash particles or between the pores formed by the fly ash and sand. The cement distribution is more uniform, and the cement dosage can be reduced, thereby reducing the friction between the sand and stone and increasing the fluidity of the cement stone. This reduces the increase in pores caused by adding excessive water due to increasing fluidity.

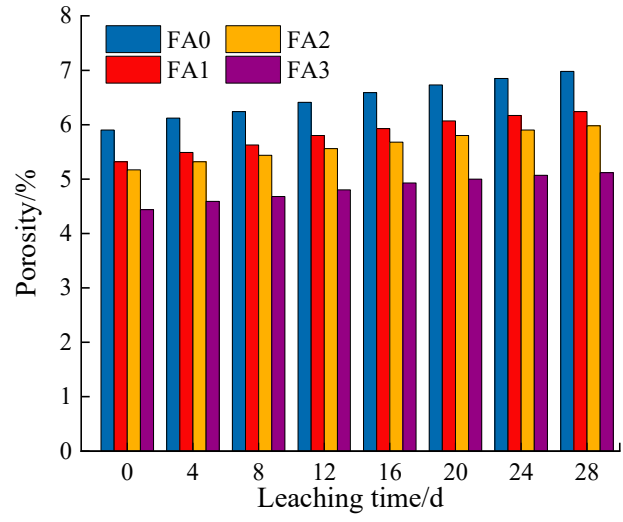

(a)

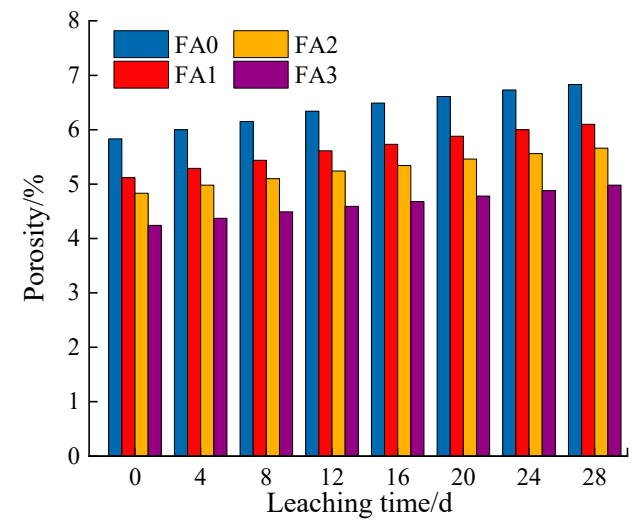

(b)

Figure 9. Cont. 


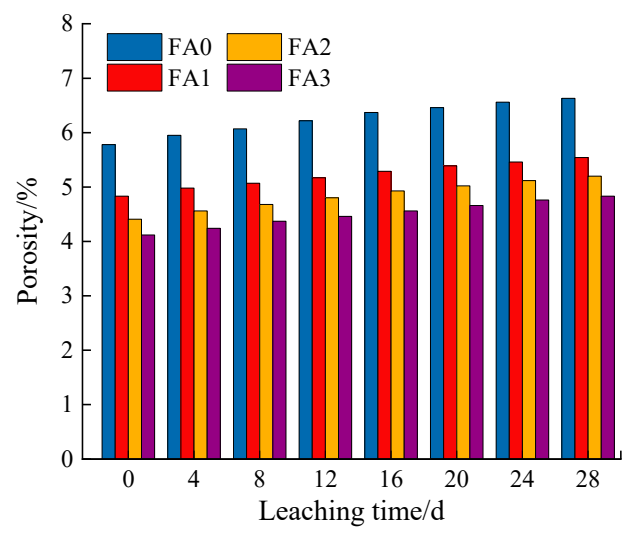

(c)

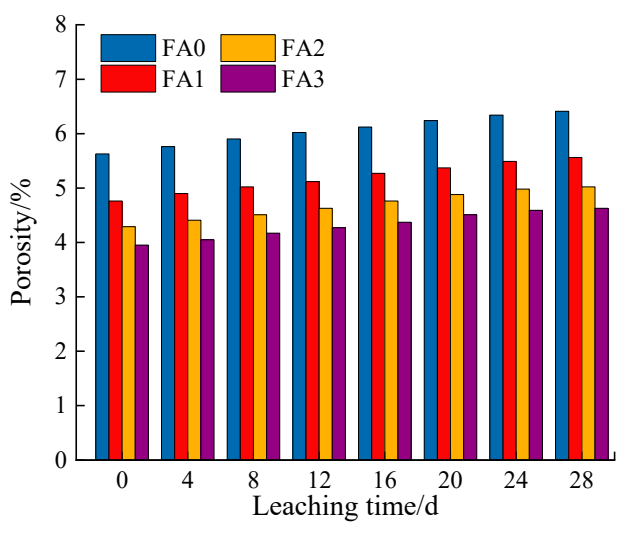

(d)

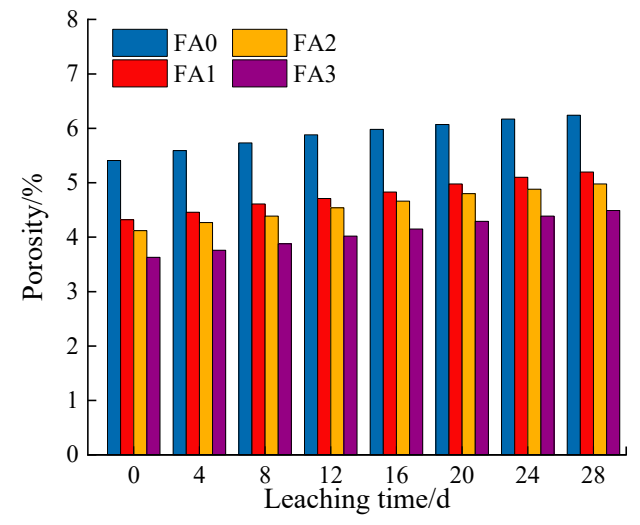

(e)

Figure 9. Porosity changes of samples with different fly ash contents: (a) cement content: 3\%; (b) cement content: $4 \%$; (c) cement content: $5 \%$; (d) cement content: $6 \%$; (e) cement content: $7 \%$.

\subsection{Permeability}

According to Figure 10a-d, the permeability coefficient gradually increased with the leaching time. According to Figures $7 a, b$ and $9 b, c$, this was mainly because the porosity increased with leaching time, leading to a gradual increase in the permeability coefficient.

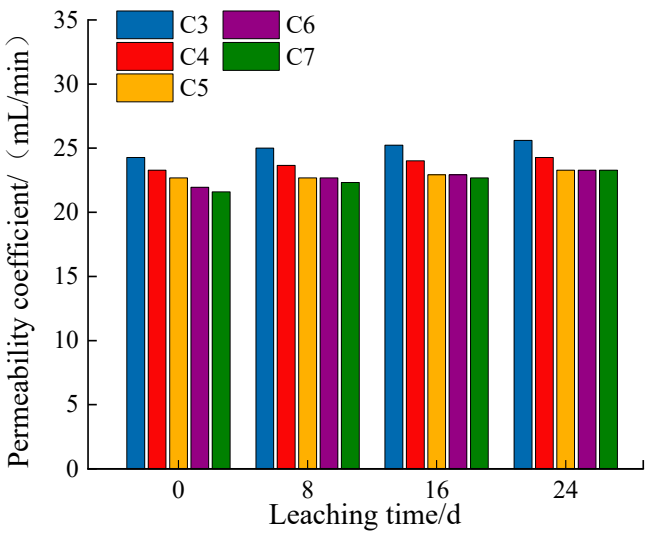

(a)

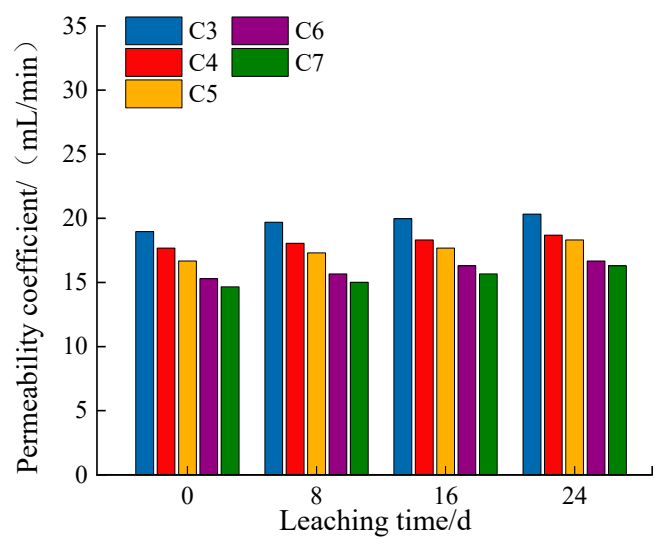

(b)

Figure 10. Cont. 


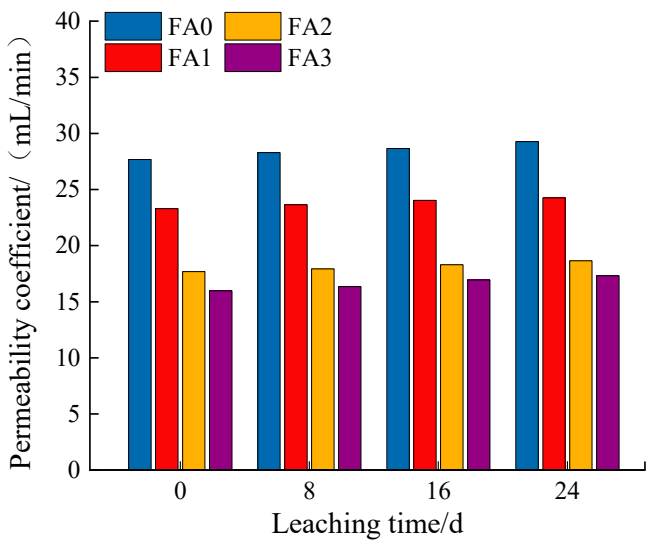

(c)

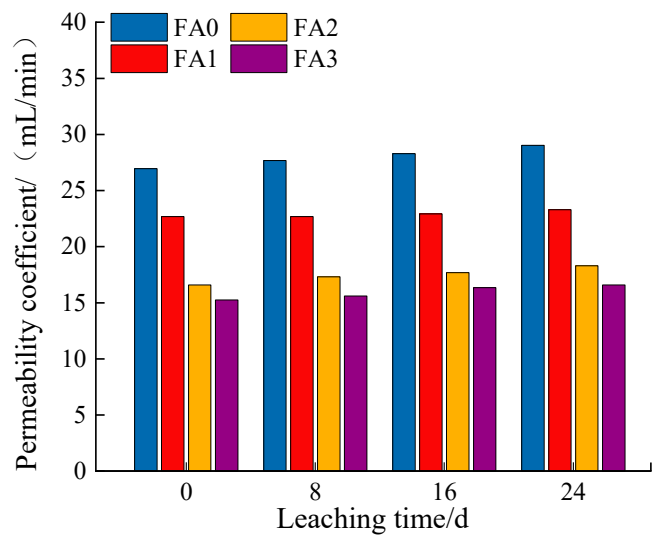

(d)

Figure 10. Change in permeability coefficient: (a) cement:fly ash $=1: 0.1 ;$ (b) cement:fly ash =1:0.2; (c) cement content: $4 \%$; (d) cement content: $5 \%$.

When the fly ash was at a constant dosage, the increase in cement dosage had little effect on the permeability coefficient. However, when the dosage of cement was constant, the addition of fly ash improved the permeability coefficient. As shown in Figures $7 a, b$ and $9 b, c$, the porosity decreased somewhat with the proportion of cement, and the porosity decreased more with the proportion of fly ash.

\section{Conclusions}

An accelerated leaching test of cement-stabilized macadam material in a $6 \mathrm{~mol} / \mathrm{L}$ ammonium chloride solution was developed. The leached calcium ion content in the solution with different cement and fly ash proportions was measured via EDTA titration. The porosity of the sample was determined using a water-dry weighing method. The permeability coefficient of the samples was measured using the variable water head method. Subsequently, the test results were analyzed. Finally, the following conclusions were drawn.

(1) During the leaching of cement-stabilized macadam material, the leaching of calcium ions increased with the cement dosage. For example, when the cement dosage was $7 \%$ and no fly ash was added, the quantity of calcium ions leached out at the early stage of leaching was significantly greater than those of the samples at other cement dosages. However, with the increase in the fly ash content, the gap between the two was significantly reduced.

(2) With an increase in the cement dosage, the porosity of the samples and the leaching rate of the calcium ions reduced, and the leaching process was delayed. The cement dosage should be at least $5 \%$ when the base material is not mixed with the fly ash. The minimum cement dosage should be $4 \%$ when the base material is mixed with the fly ash.

(3) The addition of fly ash can effectively reduce the degree of calcium leaching. However, the effect of fly ash was not the same with different cement dosages. When the cement dosage was $3 \%$, the addition of fly ash did not significantly reduce the leaching of calcium ions. When the cement dosage was greater than $3 \%$, the slow-down effect of the fly ash on calcium ion leaching increased continuously with the cement dosage in the test samples.

(4) In the leaching process of the cement-stabilized macadam material, the permeability coefficient increased gradually with the leaching time. Therefore, the increase in fly ash content had a more significant effect on the improvement of the permeability coefficient than the increase in cement dosage did.

The test results showed that the incorporation of fly ash can reduce the extent of calcium ion leaching and porosity of the cement-stabilized macadam, reduce the mate- 
rial's permeability, and improve the leaching durability and structural life of the cementstabilized macadam base. In addition, the study of its influence on cement-stabilized macadam can improve the application of fly ash and guide engineering applications in obtaining the best mineral mixture.

Author Contributions: Conceptualization, T.Y.; formal analysis, X.Y.; investigation, M.P.; data curation, J.S.; writing—original draft preparation, D.L.; writing—review and editing, X.Y.; funding acquisition, H.R. All authors have read and agreed to the published version of the manuscript.

Funding: This research was funded by the Guangxi Science and Technology Innovation guidance Project, grant number AC10380107.

Institutional Review Board Statement: Not applicable.

Informed Consent Statement: Not applicable.

Data Availability Statement: The study did not report any data.

Acknowledgments: This study was financially supported by the Guangxi Science and Technology Innovation guidance Project (Grant No. AC10380107). The authors thank the reviewers of this paper for their comments and suggestions.

Conflicts of Interest: The authors declare no conflict of interest.

\section{References}

1. Chunling, G. Degradation Mechanism of Concrete Due to Calcium. Master's Thesis, Zhejiang University, Zhejiang, China, March 2012.

2. Xinzhu, Z; Lingyan, Y.; Jianjun, Z. An experimental study on the degradation of mechanical properties leached concrete. J. Zhejiang Univ. Technol. 2016, 44, 524-528.

3. Xiangzhi, K.; Gaixin, C.; Guojin, J.; Shuguang, L. Experimental study on accelerating effect of ammonium nitrate on the calcium leaching of dam concrete. Concrete 2017, 4, 34-37.

4. Chongbo, G. Fracture Parameter Analysis of Concrete Subjected to Calcium Leaching. Master's Thesis, Zhejiang University, Zhejiang, China, March 2018.

5. Zhongzheng, D. Research on Dissolution Characteristics and Deterioration Mechanism of Complex Cementitious Materials. Master's Thesis, Changjiang River Scientific Research Institute, Wuhan, China, June 2017.

6. Haiyan, S. Study on FA Critical Dosage of Hydraulic Concrete Based on the Microstructure Characteristic and Deterioration Mechanism. Master's Thesis, Wuhan University, Wuhan, China, May 2010.

7. Shuangxin, S. Research on Leaching Behavior of Plastic Concrete Based on Electrochemical Accelerating Mechanism. Master's Thesis, Harbin Institute of Technology, Harbin, China, June 2011.

8. Faucon, P.; Le Bescop, P.; Adenot, F.; Bonville, P.; Jacquinot, J.; Pineau, F.; Felix, B. Leaching of cement: Study of the surface layer. Cem. Concr. Res. 1996, 26, 1707-1715. [CrossRef]

9. Faucon, P.; Adenot, F.; Jacquinot, J.; Petit, J; Cabrillac, R.; Jorda, M. Long-term behaviour of cement pastes used for nuclear waste disposal: Review of physico-chemical mechanisms of water degradation. Cem. Concr. Res. 1998, 28, 847-857. [CrossRef]

10. Haga, K.; Sutou, S.; Hironaga, M.; Tanaka, S.; Nagasaki, S. Effects of porosity on leaching of Ca from hardened ordinary Portland cement paste. Cem. Concr. Res. 2004, 35, 1764-1775. [CrossRef]

11. Tognazzi-Lawrence, C. Couplage Fissuration-Dégradation Chimique Dans Les Matériaux Cimentaires: Caractérisation ET MO-Délisation. Ph.D. Thesis, INSA, Toulouse, France, 1998.

12. Hassan, B.; Tiefeng, C.; Miao, R.; Xiaojian, G.; Anshuang, S. Influence of silica fume, metakaolin \& SBR latex on strength and durability performance of pervious concrete. Constr. Build. Mater. 2021, 275, 122124.

13. Song, Z.; Liu, Y.; Jiang, L.; Guo, M.; Chen, J.; Wang, W.; Xu, N. Determination of calcium leaching behavior of cement pastes exposed to ammonium chloride aqueous solution via an electrochemical impedance spectroscopic approach. Constr. Build. Mater. 2018, 196, 267-276. [CrossRef]

14. Amenta, M.; Karatasios, I.; Psycharis, V.; Maravelaki, P.; Kilikoglou, V. The leaching mechanism of hydraulic mortars as part of autogenic self-healing process. J. Cult. Herit. 2020, 46. [CrossRef]

15. Long, W.-J.; Ye, T.; Gu, Y.-C.; Li, H.-D.; Xing, F. Inhibited effect of graphene oxide on calcium leaching of cement pastes. Constr. Build. Mater. 2019, 202, 177-188. [CrossRef]

16. Ferdous, W.; Manalo, A.; Siddique, R.; Mendis, P.; Zhuge, Y.; Wong, H.S.; Lokuge, W.; Aravinthan, T.; Schubel, P. Recycling of landfill wastes (tyres, plastics and glass) in construction-A review on global waste generation, performance, application and future opportunities. Resour. Conserv. Recycl. 2021, 173, 105745. [CrossRef]

17. Yuehong, M. Characteristics and comprehensive utilization of fly ash. Northwest China Electr. Power 2004, 3, 45-48. 
18. Ferdous, W.; Manalo, A.; Aravinthan, T.; Van Erp, G. Properties of epoxy polymer concrete matrix: Effect of resin-to-filler ratio and determination of optimal mix for composite railway sleepers. Constr. Build. Mater. 2016, 124, 287-300. [CrossRef]

19. Peng, Y.; Allan, M.; Wahid, F.; Rajab, A.; Choman, S.; Tom, H.; Peter, S. Investigation on the physical, mechanical and microstructural properties of epoxy polymer matrix with crumb rubber and short fibres for composite railway sleepers. Constr. Build. Mater. 2021, 295, 123700.

20. Kunhe, F.; Yan, R.; Li, Z. Late-age properties of RCC with low cement content and high fly ash content. J. Hy-Droelectr. Eng. 1999, $04,18-25$.

21. Rozière, E.; Loukili, A.; El Hachem, R.; Grondin, F. Durability of concrete exposed to leaching and external sulphate attacks. Cem. Concr. Res. 2009, 39, 1188-1198. [CrossRef]

22. Shaoli, H. Experimental Study on Corrosion Behavior of Mineral Sdmixture Concrete in Soft Water. Master's Thesis, Nanjing University of Science \& Technology, Nanjing, China, 2019.

23. Zhengqing, F.; Yujuan, T.; Shaoli, H.; Haiquan, Z. Influence of fly ash on leaching behavior of cement paste. Low Temp. Archit. Technol. 2018, 40, 9-13.

24. Gérard, B.; Le Bellego, C.; Bernard, O. Simplified modelling of calcium leaching of concrete in various environments. Mater. Struct. 2002, 35, 632-640. [CrossRef]

25. Nguyen, V.H.; Nedjar, B.; Torrenti, J.M. Chemo-mechanical coupling behaviour of leached concrete. Nucl. Eng. Des. 2007, 237, 20. [CrossRef]

26. Wan, K.; Li, L.; Sun, W. Solid-liquid equilibrium curve of calcium in $6 \mathrm{~mol} / \mathrm{L}$ ammonium nitrate solution. Pergamon 2013, $53,44-50$.

27. Wan, K.; Li, Y.; Sun, W. Experimental and modelling research of the accelerated calcium leaching of cement paste in ammonium nitrate solution. Constr. Build. Mater. 2012, 40, 832-846. [CrossRef]

28. Taylor, H. The Chemistry of Cements; Academic Press; Elsevier: Cambridge, MA, USA, 1964.

29. Guodong, L. Characteristics of Structure, Shape and Activity of Fly Ash. Fly Ash Compr. Util. 1998, 3, 37-40.

30. Congling, W.; Ling, P.; Qingrong, W.; Shaofeng, W. Experimental research about the permeability and corrosion of fly ash concrete with different rate of cao/Sio2 on the condition of pressured water. J. Wuhan Univ. Technol. 2000, 1, 25-27.

31. Shaikh, F.; Supit, S. Compressive strength and durability properties of high volume fly ash (HVFA) concretes containing ultrafine fly ash (UFFA). Constr. Build. Mater. 2015, 82, 192-205. [CrossRef]

32. Xiao, H.; Jingjing, F.; Chuanzhen, S.; Shanshan, W. Research on properties of ultrafine fly ash and cement cementitious materials under curing at $50{ }^{\circ} \mathrm{C}$. J. Build. Mater. 2021, 24, 473-482.

33. Martin, L.H.; Winnefeld, F.; Tschopp, E.; Müller, C.J.; Lothenbach, B. Influence of fly ash on the hydration of calcium sulfoaluminate cement. Cem. Concr. Res. 2017, 95, 152-163. [CrossRef] 